Session 2602

\title{
Adapting Graduate Degree Programs to the Distance Learning Environment
}

\author{
Daniel Biezad, Jin Tso \\ Aerospace Engineering Department \\ California Polytechnic State University at San Luis Obispo
}

\begin{abstract}
A new graduate aerospace engineering program has been implemented for the distance-learning environment at California Polytechnic State University, San Luis Obispo. The program is fully accredited and strives to maintain the hands-on "learning by doing" educational philosophy at Cal Poly. It has been in operation for two years and will award its first graduate degree in 2001 to students working at Vandenberg Air Force Base, California. The program is unusual in that it developed from within the aerospace engineering faculty with full faculty support. Several important lessons and pitfalls in the program development and in obtaining accreditation are described in the paper. Foremost among these are issues of faculty ownership of educational materials, faculty training requirements for the distance learning environment at the graduate level, course scheduling so that the students can graduate in two years, integrating the web into lecture and laboratory courses, and funding negotiations with the administration. The paper concludes with a few strong recommendations for other institutions implementing graduate-level distance- learning programs.
\end{abstract}

I. Introduction

"Every country understands that engineering must be made more exciting as a profession."

Ernest T. Smerdon ${ }^{1}$

The above wake-up call by a past president of the ASEE emphasizes that engineering education is not only rapidly changing the world, but is itself being dramatically transformed by those changes. Continuing education is now big business, fueled by information technology and recognized as essential by professional and politician alike. ${ }^{2}$ The $e$-learning market is expected to top 5 billion annually by 2002 , despite the current tribulations of "dot.com" start-ups and despite the varied complaints from entrenched faculty ("It's like teaching through a straw." ${ }^{3}$ ). The bottom line is that, thanks to the internet, professionals can now keep pace and advance with technology and management despite heavy work commitments.

The difficulty, of course, is that the internet can be used by frauds and diploma mills as well as by legitimate institutions. The federal government has traditionally followed a 12-hour and 50percent rule; that is, to get financial aid students must take at least 12 hours of instruction per 
week and no more than half of the courses may be at a distance. ${ }^{4}$ Copyright law is also a "horse and buggy" on the information superhighway, many times requiring professors to tediously obtain permission to use materials on the web that they otherwise freely use in a classroom setting. In order to maintain quality without being left behind, educational institutions initiating distance learning programs must often rethink their mission and strategy. This paper describes this process for an institution proud of its heritage for providing a quality, "hands-on," and fully accredited engineering education.

For almost two years now, the Aerospace Engineering Department at California Polytechnic State University (Cal Poly), San Luis Obispo, has been offering a Master of Science degree program via distance learning to an off-campus site at Vandenberg Air Force Base (VAFB), about 60 miles south of Cal Poly. The M.S. in Aerospace Engineering program is in demand by working engineers and Air Force officers at VAFB. It gives them needed access to advanced training that will benefit their professional growth and careers.

So far, about 15 graduate students have been enrolled at the VAFB site. They are mostly parttime, adult learners consisting of engineers and Air Force officers. The off-campus site has the same curriculum and faculty as the main campus. During the fall, winter, and spring quarters, courses are offered via video teleconferencing and during the summer quarter via on-site teaching. The courses are typically offered in the evening to accommodate the students' working schedules.

This program is unusual in that it is developed from within the Aerospace Engineering Department faculty with full faculty support. It is also the first graduate degree program offered by Cal Poly via distance learning. The program is fully WASC accredited and strives to maintain the hands-on "learning by doing" educational philosophy at Cal Poly. To uphold this educational philosophy in distance learning, however, has been quite challenging and requires new thinking.

\section{Program description}

"Engineers tell me that they need a thorough refresher course in their specialties at least every other year." $\quad$ Peter Drucker ${ }^{3}$

\section{II.1 Program concept}

The distance learning program we developed provides students at VAFB an access to advanced training at the master's degree level in aerospace engineering. By design, it has the same faculty, curriculum, class schedule, and catalog as the main campus. All students at VAFB are considered regular Cal Poly students. They apply directly to Cal Poly's main campus, and the faculty and graduate coordinator of the Aerospace Engineering Department make the admission decision, just like for any other on-campus students. Also like the existing M.S. degree program at the main campus, the VAFB program is not offered as a cohort model. Students can enroll at the beginning of any quarter to start the graduate program. 


\section{II.2 Learning objectives and expectations}

The M.S. program at VAFB has the same learning objectives and expectations as the main campus. It is a two-year, 45 quarter-unit program, of which 29 units are for required courses and 9 units for thesis or design project. The first year of the program is for students to take advanced courses in basic fields related to astronautical engineering. The thesis project is typically done in the second year. Since the students at VAFB are mostly working engineers and Air Force officers, they are encouraged to take two courses per quarter, including the summer quarter. They are also expected to develop strong skills in oral and written communication.

\section{3 Accreditation process}

Almost immediately after receiving the Request for Proposal to Offer On-base Programs from the Air Force at Vandenberg AFB on February 27, 1997, the faculty in the Aerospace Engineering Department expressed a strong interest to pursue the program. But before the program proposal was submitted to the Western Association of Schools and Colleges (WASC) for accreditation review, the Aerospace Engineering faculty, the College of Engineering and the university administration had undergone a long and tedious preparation.

Following the Off-Campus and Substantial Change Application Manual published by WASC, the faculty's first task was to define the new program. To ensure the quality and image of the program, the faculty in our program adopted the idea to have the same faculty, curriculum, class schedule, and catalog as the main campus. This means that all students at VAFB are considered regular Cal Poly students. We also discarded the option to offer the program via Extended Education. In hindsight, this was a crucial step in obtaining program accreditation.

During the long preparation process, most challenges we encountered were internal. At that time, there were individual faculty members on campus offering distance learning courses via Extended Education. However, there were no degree programs offered via distance learning. The decisions about when and how to offer a course were largely left to those faculty members who taught the course. But for a degree program, it is a very different matter. We must first have the support of the entire faculty of our department. Fortunately, because the proposed distance-learning degree program was considered as a natural vehicle to strengthen our budding space curriculum and to increase our graduate enrollment, it was endorsed quickly by the faculty. Afterward, most work was about financial and faculty support to the program.

The program proposal was submitted to the WASC for review on May 26, 1998. On June 17, 1998 the associate deans of the college and the department chair had a meeting at San Francisco with the WASC Accreditation Committee members. The meeting discussions were largely focused on the academic quality of the distance learning program and the support to the offcampus students. Our program design to have the same faculty, curriculum, class schedule, and catalog as the main campus certainly eased the first concern. Our willingness to take extra steps to communicate with the off-campus students also eased the second concern. 
We received the official accreditation notification on July 15, 1998. The Accreditation Committee commended the proposal as well crafted, thorough and informative. The program started offering the first course in spring, 1999 after the final approval of the program by the Air Force. As part of the WASC accreditation process of Cal Poly last year, the distance-learning program was reviewed last fall by the visiting WASC accreditation team and received favorable comments.

III. Faculty development

"For the college professor, a chief concern is how much extra time will be consumed by producing and teaching a Web-based course." Robert Ubell

III.1 Educational philosophy and paradigm

To uphold the "learn by doing" hands-on educational philosophy in distance learning has been quite challenging to say the least. Our department faculty determined at the outset not to substitute power point view graphs for meaningful insight that comes from concentration and effort. Although studies have shown no significant difference in the learning outcomes of conventional classes vs those in an "e-learning" environment", these studies almost always cite the results of written exams or submitted papers, and not the expertise that comes from a laboratory "hands-on" approach to learning.

The difference between resident students and distance learners taking the same class can be significant. First there is the learning curve that must be mastered, the familiarity with computers and applications that is taken for granted by the resident students but strange to students in a distance-learning environment. Then there is the synergism of the students themselves, a significant benefit of campus life that is difficult to create in a distance-learning classroom. Finally, there is the practical difficulty of demonstrating lab processes and equipment via television or the internet. Take the simple example of a GPS navigation receiver, one that can be passed around the classroom, taken outside for demonstrations of satellite lock, and hooked to other differential receivers. In "e-learning" it is not feasible to provide these experiences.

\section{III.2 Integration with web tools}

In a distance learning environment, refresher courses must not only be updated, but they must be presented in new formats that are challenging in themselves for faculty to use. Popular "elearning" models currently include "portals" where internet providers may market an institution's courses for a fee, "templates" provided by vendors so that colleges may prepare and administer their own web courses, and many variations of "portals" and "templates" including commercial advertising and content providing arrangements. 8 Although information technology services (ITS) at Cal Poly has made the "template" called "Blackboard" available to faculty, our department has preferred to use an electronic white board combined with computer graphics and applications. This allows the traditional approach to teaching to be combined with powerful tools for visualization and information transfer. 


\section{III.3 Faculty training}

Not all educators take to distance learning. On-line learning can never replace the ambiance of campus life, can never provide "distinct ways of judging what is interesting, valid, significant." 5 A few educators have even argued that teaching by its nature is slow, labor-intensive, and by its very inefficiency allows learning to take place. ${ }^{6}$

In order to enlist the support of our department's entire faculty, release time was provided along with funded assistance in preparing computer-aided materials suitable for distance learning. Faculty were trained in multi-media classrooms using large video displays, electronic white boards, Elmo projection, and the projection of computer graphics and applications. It typically took a few weeks to become familiar with the equipment, and this had the positive benefit of making professors rethink their courses. They added web-site construction, upload and download of educational materials, and file-transfer skills to their set of educational tools.

\section{III.4 Ownership of educational materials}

The legal system has yet to catch up with the explosion of educational materials available on the web. Faculty need protection from the threat of a lawsuit every time they post material on a web site that is identical to material they routinely use in a class on campus. They also need protection from the pirating of their own material, not only from others on the internet, but also from their own institution. The courts are still to be heard on this issue, but it is safe to say that faculty must insist on some written assurance that their materials will not be packaged or sold without their participation in the resulting revenues.

IV. Student learning

"Chalk, hopelessly old-fashioned, by its very inefficiency helps to slow down he information flow and allows learning to take place." Michael Randall

\section{IV.1 Supportive learning environment}

From the very beginning of this program, we have realized the critical importance of a supportive environment to the off-campus students. In fact, it was a major concern for the WASC accreditation of our program. Fortunately, almost all of the military and civilian personnel at VAFB have access to the internet. This makes it easy for them to access Cal Poly's e-mail system, web site, and other on-line resources. Students at VAFB are given information and instructions on-line regarding registration, class scheduling, course descriptions, library, and other available services. We also took steps to make sure that their questions are answered expediently. Furthermore, we held gatherings so the VAFB students could meet their faculty and fellow on-campus classmates.

As to library and other information resources, we have a program library at VAFB where the faculty can provide the most often used course reserves and assigned readings for students to 
use. Through the reserve service provided by the on-base public library, additional course materials and assigned readings may be held on reserve at instructor's discretion in the campus library. Where necessary, documents can be delivered by courier (like Federal Express), fax, mail, e-mail, or direct downloading from the Internet. Furthermore, PC workstations loaded with the course software have been installed on site at VAFB for student use.

\section{IV.2 Faculty/students interactions}

For distance learning, most communications between faculty and students outside the classroom are via e-mails. Students can submit their questions at any time of the day and faculty can respond to those questions when they have time. This is certainly its biggest advantage. Possibly because of the writing involved in e-mails, the questions raised and the answers given tend to be more organized and thorough.

What e-mails lack, however, are the spontaneity and the body language typical in face-to-face interactions. A handy drawing on a piece of paper to illustrate a concept or a hand gesture to convey an idea can hardly be done by e-mails. A scanned file, a fax or a phone call has helped to ease such gaps but is still far from ideal. Personal meetings with the faculty, though desirable, are not always convenient to arrange. For a while, it seemed that having office hours in the distance learning rooms could be a reasonable solution. This idea, however, is not appealing to the faculty because it requires them to stay in the distance-learning room at odd hours in the evenings. An alternative solution is to install a web-camera, microphone and multimedia software in each faculty office to allow such communications. Since this option would require similar equipment on the student side, it is yet to be implemented.

To compensate for the lack of face-to-face interactions in distance learning, the faculty have been traveling to teach on base in summer. This is feasible only because few resident students stay on campus during the summer. If the program were later expanded to more than one offcampus site, this would no longer be a feasible option.

\section{IV.3 Assessment of student learning}

Our program is subject to periodic WASC accreditation reviews on learning objectives, pedagogy, faculty quality and evaluation, and student achievements. Our efforts to strive for a supportive learning environment and better face-to-face interactions with students have received high remarks from the WASC. Student evaluations are routinely conducted at the end of each quarter to evaluate the performance of each course and instructor. In such assessments, our basic concern is whether the student learning is equally effective and efficient for both oncampus and off campus students.

Table 1 shows the grade distributions of all the courses that have been offered so far to VAFB. Overall, the grades of the Vandenberg AFB students appear to compare well with on-campus students. In the distance-learning rooms, the distance-learning students listen to the lectures, write down the notes and ask questions just like on-campus students. Their homework and tests have shown no gaps in learning performance. From the learning's perspective, we could claim 
that the distance learning has been equally effective for both on-campus and off-campus students.

However, it is a quite different matter for learning efficiency. Without the face-to-face elements, it is indeed harder sometimes for off-campus students to communicate with instructors. The learning process is especially troublesome when dealing with labs. Our inputs from students have clearly shown their frustrations in this aspect. To remove the lab requirements from the off-campus students, however, is not an acceptable option, as it would defeat the purpose of our program of "hands-on" education. We have investigated the possibility of a separate lab at the off-campus site. Because of its additional funding requirement, this option has not been pursued.

Table 1 Grade comparison between VAFB and on-campus graduate students

\begin{tabular}{|l|c|c|c|c|}
\hline & $\mathrm{A}$ & $\mathrm{B}$ & $\mathrm{C}$ & $\mathrm{D}$ \\
\hline On-campus & $77 \%$ & $23 \%$ & $0 \%$ & $0 \%$ \\
\hline VAFB & $83 \%$ & $9.5 \%$ & $7.1 \%$ & $0 \%$ \\
\hline
\end{tabular}

V. Administrative support

"A university is what a college becomes when the faculty loses interest in students" John Ciardi

\section{V.1 Class scheduling}

With our limited manpower in the department, it has been a challenge to schedule the distancelearning courses. The primary mandate for distance-learning class scheduling is that we must offer enough courses each quarter so the students can graduate in two years. In order to accommodate the working schedules of the students at VAFB, the courses have been offered typically from $5 \mathrm{pm}$ to $7 \mathrm{pm}$ in the evening. During the regular fall, winter, and spring quarters, the courses are conducted via two-way interactive teleconferencing in the distance learning rooms at Cal Poly and VAFB. During the summer quarter, the courses have been scheduled on site at VAFB to add the face-to-face elements to the distance-learning program.

The evening course schedules, however, are hardly the favorable time for the faculty. This class scheduling has placed tremendous pressure on the faculty. To schedule the distance-learning lab courses poses another challenge. For labs to be done on computers, the scheduling is similar to that for the lecture courses. We have scheduled physical labs on Saturdays so the VAFB students can travel to campus one morning/afternoon per week to conduct the tests. This has not been appealing to either the students or the faculty. Since we do not have the funding to duplicate the labs at the off-campus site, this remains a significant problem.

So far, we typically schedule two courses per quarter. Assuming four quarters per year and four units per course, we can easily meet the 20 unit course requirements in math/numerical methods, aerodynamics, propulsion, structures and control areas for the master's degree within one year. The students can use the remaining year for their theses and electives. In reality, however, not 
every student takes two courses as planned. In fact, because of their jobs, most working engineers take one course per quarter. This immediately put pressure on the enrollment target of each class. During the fall, winter and spring quarters on-campus senior and graduate students could compensate the weak enrollments. Summer, however, is a very different story.

The weak summer enrollment has been problematic during our two years of running this program.

From the student's perspective, some of them have family and would like to have a break in summer. The same is true for the faculty. To request a faculty member to stay in summer only for a summer course is not an attractive offer. We have underestimated the seriousness of this issue until we encountered a very low enrollment last summer.

A solution to this problem is to offer a five-week or even shorter summer quarter. This option provides the students and their families an opportunity to enjoy a summer break. It also allows the faculty a much better opportunity to use their summer time. This is especially important for those faculty members who plan to work in industry or a national institute like NASA as they must start their planning early in winter or spring quarter. A last minute canceling of a summer class is an option that must be avoided by all means.

\section{V.2 Importance of university commitment}

Even with all the enthusiasm and hard work by the faculty, the program will not succeed without strong financial commitment and administrative support from the university. The students at VAFB pay a lab fee for distance learning, and the costs for upgrading certain telecommunication facilities at VAFB are shared by Vandenberg AFB. Still, for a state institution constantly facing financial uncertainty, this commitment was difficult to make. The primary concerns were enrollment uncertainty and faculty compensation.

It has been the goal of the university that the program will eventually be self-sustained financially. To make this happen, a distance-learning fee was included for each course to cover the costs for technicians, office operation, equipment, and faculty summer compensation. This plan would work if we meet a certain average enrollment target per course. As we found out very soon, most Air Force officers are not California residents. In the California State University system, the non-resident students still have to pay the out-of-state tuition or given one-year grace period to become a California resident. Most Air Force students decline the latter option. Since the Air Force only subsidizes the educational costs up to a certain limit, the outof-pocket costs could be prohibitive for some to enroll in our program. The immediate consequence is a slower enrollment growth of Air Force students in our program. On the other side, most civilian engineers are California residents. Unlike Air Force officers, they do not face the pressure of being transferred to other states in three years. Nonetheless, due to their heavy workloads, they typically take only one course per quarter. These two factors certainly have not helped us build up the enrollment fast enough. In a situation like this, a firm support from the university is crucial to the survival and long-term success of our program. 
The initial investment on teleconferencing equipment is another area where the university must play a major role. As we have learned, it is important to convince the administration at the early stage that the best strategy is to consider such investment as part of the university's long-term distance-learning plan. The same teleconferencing equipment can be shared by different programs and allow the university to reach larger population at a cheaper cost. It is crucial not to let the administration to fall into the thinking that it is an investment on a single program and to seek near-term return. Such thinking could easily jeopardize the faculty confidence and leads to early failure of the program. We would never reach even today's moderate success if the university had not committed to the equipment and its maintenance at the early stage.

In addition to the teleconferencing equipment, investment on faculty training and staff support are another crucial areas for administrative support. Many faculty members are used to the traditional classrooms with chalkboards, with the homework turned in on paper and the tests taken in classrooms. All of these change in distance learning. The faculty now need to learn how to teach in the multimedia distance-learning classroom. They need to become adept at the camera, projector, video player and various multimedia software. They need to place their homework and solutions on the web and answer most of the questions via e-mails. All of these need training.

Cal Poly does provide training on multimedia web course useful for distance learning. So far, the response from the faculty has not been strong. The primary reason is the time the faculty do not have to commit themselves to the new multimedia teaching. Adequate release time for the faculty and strong staff support are essential to make any major progress in this direction.

VI. Concluding remarks

$$
\begin{aligned}
& \text { "The one who comes to teach learns the keenest of lessons, } \\
& \text { while those who come to learn learn nothing." J. M. Coetzee }
\end{aligned}
$$

It is important to guard against cynicism in on-line education, a cynicism that may arise from either the student's or the professor's point of view. An overemphasis on marketing, administration, financial return, multi-media technologies, and the computer can disrupt the relationship between professor and student, leaving them alienated both from each other and from their institutions.

The faculty in our department have made tremendous investment on the distance-learning program and have achieved a moderate success. The program now has a strong space curriculum enriched with new and upgraded courses. The enrollment growth, though moderate, has made our graduate program more economical. The process has also been a great catalyst to encourage the faculty to convert their course materials into the new multimedia format. From the program's perspective, it is definitely worth the effort.

As to the program's future, despite all the difficulties encountered so far, we are optimistic about continuous enrollment growth of VAFB students. This growth can be attributed to several reasons. First, it is a degree program. To many Air Force personnel and civilian engineers, what they want is a master's degree to advance their professional careers. Second, the degree program 
has a strong curriculum and is offered by a strong engineering school in the region. Third, the curriculum places balanced emphasis on both engineering basics and applications that suit those students who have worked in industry or in the military. Finally, the distance learning through teleconferencing is still a better option in many ways than a video or web course. As long as it is affordable, it is still a far better choice to learn in a group environment where you can discuss with the teachers and work together with fellow students. For some students, it is perhaps the reason that they can sustain the demanding academics after a long work day.

As we look forward, we will continue to strive for a supportive learning environment and better face-to-face interactions that are essential to quality distance learning. We will continue to work on a more effective and efficient means for distance learning labs. We believe that the faculty compensation for the distance-learning program is still far from ideal. Incentives must be given to the faculty to award their initiatives and efforts to develop a successful distance learning program.

Bibliography

1. Smerdon, Ernest T., "Last Word," ASEE Prism, Volume 10, Number 5, January 2001, page 68.

2. Symonds, William C., "Education," Business Week, January 8, 2001, page 136.

3. Ubell, Robert, "Engineers Turn to E-Learning," IEEE Spectrum, Volume 37, Number 19, October 2000, pages 59-63.

4. Carnevale, Dale, "Commission Says Federal Rules on Distance Education Must Be Updated," The Chronicle of Higher Education, January 5, 2001.

5. Brown, John Seely, and Paul Duguid, The Social Life of Information, Harvard Business School Press, 2000.

6. Randall, Michael, "A Guide to Good Teaching: Be Slow and Inefficient," The Chronicle of Higher Education, Point of View, November 2000.

7. Coetzee, J.M., Disgrace, Viking Press, 1999.

8. Johnstone, Sally M., "Making Sense of the .com Phenomenon," Syllabus, December, 2000, page 21 .

DAN BIEZAD

Dan Biezad is a professor in the Aerospace Engineering Department at California Polytechnic State University, San Luis Obispo. His research areas are stability and control, flight simulation, and the flying qualities of piloted aircraft.

\section{JIN TSO}

Jin Tso is chair of the Aerospace Engineering Department at California Polytechnic State University, San Luis Obispo. His research areas are aerodynamics, turbulence, and low gravity. 